\title{
Yabancı Ot Mücadelesinde Bazı Aromatik Bitkilerinin Uçucu Yağlarının Allelopatik Etkisi
}

\author{
Ferit Özen $^{1 *} \quad$ Gülsüm Yaldız $\quad$ Mahmut Çamlıca² \\ ${ }^{1}$ Abant İzzet Baysal Üniversitesi, Mudurnu Süreyya Astarcı Meslek Yüksekokulu, Bolu \\ ${ }^{2}$ Abant İzzet Baysal Üniversitesi, Ziraat ve Doğa Bilimleri Fakültesi, Tarla Bitkileri Bölümü, Bolu \\ Geliş tarihi (Received): 14.11.2016 Kabul tarihi (Accepted): 06.01.2017
}

\section{Anahtar kelimeler:}

Tıbbi ve aromatik bitkiler, uçucu yağ, allelopati, biyoherbisit

\section{*Sorumlu yazar}

ferit_ozen@hotmail.com

Özet. Tarımsal üretimde verim ve kaliteyi artırmak amacıyla yabancı ot mücadelesinde herbisitlerden yoğun bir şekilde yararlanılmaktadır. Fakat kullanılan herbisitlerin çevreye ve insan sağlığına olan potansiyel zararı büyük bir problem olarak karşımıza çıkmaktadır. Ayrıca son zamanlarda önemi giderek artan organik tarımda kimyasal herbisitlerin kullanılmaması yabancı ot mücadelesini zorlaştırmaktadır. Bu nedenle yabancı otlarla mücadelede kimyasal mücadeleye alternatif olabilecek, çevre dostu mücadele yöntemlerinin bulunması önemli hale gelmiştir. Bu alternatif yöntemlerden biri de aromatik bitkilerden elde edilen uçucu yağlar gibi allelopatik etkiye sahip maddelerin yabancı otların mücadelesinde kullanılmasıdır. Uçucu yağlar pek çok kimyasal bileşenden oluşur. Tüm bileşenlerin yapısı ve fizyolojik etkileri benzer değildir. Uçucu yağların yapısında yer alan bileşenlerin herbisit olarak kullanılmalarına ilişkin en başarılı sonuçlar terpenlerden elde edilmiştir. Bu bileşenlerin etkilerinden faydalanılarak organik tarımda kullanılabilecek çevreye dost biyoherbisitlerin geliştirilmesi çok sayıdaki araştırıcı tarafından da vurgulanmıştır. Bu derlemede aromatik bitkilerden elde edilen uçucu yağların yabancı otlar üzerine olan etkileri incelenerek, uçucu yağların yabancı otlarla mücadelede kullanılma olanaklarına vurgu yapılacak ve kimyasal mücadelenin yerini alabilecek alternatif yaklaşımların yaygınlaşmasına katkıda bulunulacaktır.
\end{abstract}

\section{Allelopatic Effects of Some Aromatic Plants Essential Oils in Weed Control}

\section{Keywords:}

Medicinal and aromatic plants, essential oil, allelopathy, bioherbicide

\begin{abstract}
Herbicides have been used heavily in weed control in order to increase the production and efficiency in agriculture. However, use of herbicides has been shown to be have potential damages on human health and environment. Besides, prohibition of the use of chemical herbicides in organic agriculture makes the struggle with weeds even harder. Therefore, it is essential that chemical herbicides should be replaced with environmentalfriendly counterparts in weed control. One of these alternative methods could be the use of essential oils representing allelopathic effects obtained from medicinal and aromatic plants in the fight against weeds. Essential oils are composed of many chemical components and not all of them have the same structures and physiological effects. The most successful results were obtained with terpenes, one of the components in essential oils, as herbicidal. Development of the environmental-friendly bioherbicides by the making use of the effects of these components were emphasized by many researchers. In this review, the herbicidal effects of the essential oils obtained from aromatic plants will be examined and possible use of essential oils in weed control will be emphasized and we aim to contribute to approaches replacing the chemical struggle to become widespread.
\end{abstract}




\section{Gíiş}

Kültür bitkileri gelişme dönemi boyunca verim ve kalitesini olumsuz yönde etkileyen birçok faktörün etkisi altındadır. Bu faktörlerin en önemlilerinden bir tanesi de yabancı otlardır. Kültür bitkilerinde bitki koruma sorunlarından kaynaklanan kayıpların yaklaşık yarısına yabancı otlar neden olmakla birlikte, bu kaybın \%10-\%90 arasında olduğu bildirilmektedir (Oerke et al., 1994; Uygur 2002; Khanh et al., 2005; Thobatsi 2009). Tarımsal üretimde verim ve kalite artışı yabancı otların etkili bir şekilde kontrol altına alınabilmesine bağlıdır. Bu nedenle yabancı otların neden olduğu kayıpları ortadan kaldırmak için yoğun bir şekilde kimyasal yabancı ot ilaçlarına (herbisit) başvurulmaktadır. Dünyada kullanılan tarımsal mücadele ilaçlarının yaklaşık \%50'sini yabancı ot ilaçları oluştururken, bu oran ülkemizde ise \%26 düzeyindedir (Dağ ve ark., 2000; Delen et al., 2005). Yabancı ot mücadelesinde akla ilk gelen yöntem kimyasal mücadeledir. Bunun başlıca nedenleri ise; kimyasal mücadelenin kısa sürede etki göstermesi, uygulamasının kolay ve diğer yöntemlere göre maliyetinin daha az olması olarak sıralanabilir (Radosevich et al., 1997). Fakat yoğun ve bilinçsiz herbisit kullanımı birtakım sağlık ve çevre sorunlarını da beraberinde getirmektedir. Ayrıca aşırı herbisit kullanımı tarımsal ürünlerde kimyasal birikimine neden olmakta ve bu ürünlerin ihraç edildiği noktalardan geri dönmesine neden olmaktadır.

Son yıllarda artan çevre bilinci ve tarımsal mücadelede kullanılan sentetik ilaçlarının insan sağlığına olan olumsuz etkileri nedeniyle yabancı otların mücadelesinde kimyasal mücadelenin yerini alabilecek, insan sağlığına ve çevreye zarar vermeyen yeni yöntemlerin bulunması önem kazanmıştır. Bu alternatif yöntemlerden biri de yabancı otlar üzerinde allelopatik etkiye sahip olan doğal bileşiklerin yabancı otların mücadelesinde kullanılmasıdır (Uludağ 2006). $\mathrm{Bu}$ alanda yürütülen çalışmalarda ise özellikle allelopatik doğal bileşiklerden olan bitkisel kökenli uçucu yağlar ön plana çıkmaktadır.

\section{YABANCI OT MÜCADELESINDE UÇUCU YAĞLARIN KULLANILMASI}

Allelopati kelimesi yunanca anlamı iki organizmanın acı çekmesi, değer kaybetmesi olan "allelo" ve "pathy" kelimelerinin birleşiminden türemiştir. Bir bitkinin sentezlediği biyokimyasallar veya bitkinin biyolojik ayrışımı sonucu oluşan maddeler ile başka bitkilerin büyüme ve gelişiminin doğrudan veya dolaylı olarak olumlu veya olumsuz olarak etkilenmesi allelopati olarak tanımlanmıştır (Rice 1984; Gholami et al., 2011; Kwiecińska-Poppe et al., 2011). Bitkiler tarafından salgılanan ve allelopatik etkiye sahip olan kimyasal maddelere ise allelokimyasal maddeler denilmektedir. Bitkilerce salgılanan sekonder metabolitlerin çoğu allelokimyasal özelliklere sahiptir (Telci 2006; Amini et al., 2012; Amini 2013; Konstantinović et al., 2014; Khan et al., 2010; Soltys et al., 2013). Sekonder metabolitler genel olarak alkaloidler, terpenoitler ve fenoller olmak üzere üç temel grupta sınıflandırılır (Baydar 2013). Allelokimyasalların herbisit olarak kullanılmalarına ilişkin en başarılı sonuçlar terpenlerden elde edilmiştir (Duke 1991). Terpenler içerisinde ise en etkili olanların monoterpenler olduğu bildirilmiştir (Robinson 1983). Bitkiler tarafından sentezlenen en önemli sekonder metabolitlerden biri olan uçucu yağların yapısında yer alan bileşiklerin de büyük çoğunluğunu terpenler oluşturmaktadır. Bu özelliklerinden dolayı uçucu yağlar son yıllarda kimyasal herbisitlere karşı alternatif allelokimyasal maddeler olarak gösterilmektedir (Abrahim et al., 2000).

Uçucu yağlar bitkilerden damıtma, tüketme ve sıkma gibi değişik yöntemler kullanılarak elde edilirler. Uçucu yağlar hangi yöntemle elde edilirse edilsin uçucu yağların çoğu uzun süre ışık ve hava ile temasa geçtiğinde oksidasyon ve polimerleşme ile bozulur (Baydar 2009; Ceylan 1997). Uçucu yağlar bitkinin tüm organında bulunabileceği gibi, sadece tek bir organında da yoğunlaşabilirler. Uçucu yağlar, biberiye, fesleğen, adaçayı gibi bitkilerin yapraklarında bulunan salgı tüylerinde, kimyon, rezene, kişniş gibi bitkilerin meyvelerinde bulunan salgı kanallarında, portakal, limon gibi türlerin kabuklarında bulunan salgı ceplerinde, kara çam, sarı çam gibi türlerin gövde kabuklarında bulunan reçine kanallarında salgılanırlar. (Handa et al., 2008).

Bitkiler için temel besin ve yapı maddeleri olmayan uçucu yağların bitkiler tarafından neden üretildikleri kesin olarak bilinememekle birlikte, bazı nedenler ileri sürülmektedir. Bu nedenlerden bazıları, kötü kokulu uçucu yağların itici özellik göstererek bulundukları bitkileri hastalık, zararlı ve ot-obur hayvanlara karşı korumaları, güzel kokulu uçucu yağların ise çekici özellik göstererek başta bal arıları olmak üzere pek çok böceği çekerek tozlaşmayı sağlamalarıdır. Ayrıca sıcak ve kurak iklim bölgelerinde yetişen bitkilerin uçucu yağların uçucu olma özelliklerinden dolayı uçma anında serinlik etkisi yaratmalarıdır. Bu nedenledir ki, sıcak iklim bölgelerinde serin iklim bölgelerine göre daha fazla uçucu yağ bitkisi bulunmaktadır (Baydar 
2005). Bunlara ek olarak, uçucu yağları oluşturan bileşiklerin çoğu antioksidant, antimikrobial, antifungal ve antibakteriyel özellik göstermeleri (Soylu et al., 2006; Soylu et al., 2009; Mengüllüoğlu and Soylu 2012; Sertkaya 2013) ve bitkilerden yayılan uçucu bileşiklerin çevredeki bitkilerin çimlenme, büyüme ve gelişimini etkileyerek kendileriyle rekabete girmelerini engellemeleri (Robles et al., 1996) gibi nedenler bu bitkilerin kendilerini dış faktörlere karşı korumak için uçucu yağ ürettiklerini düşündürtmektedir.

Uçucu yağların çimlenme, büyüme ve gelişim engelleyici olarak doğada allelopatik etkilere sebep olması (Reynolds 1987), uçucu yağların aynı zamanda yabancı otların mücadelesinde alternatif allelokimyasallar olabileceği sonucunu doğurmuştur. Yapılan çalışmalarda uçucu yağların yabancı otlar üzerine başlıca allelopatik etkilerinin tohumların çimlenmesinin engellemesinin yanında, yabancı otların büyüme ve gelişmesini yavaşlatması olduğu bildirilmektedir (Feo et al., 2002; Barney et al., 2005). Uçucu yağların bu etkilerinin temelinde farklı fizyolojik nedenler yatmaktadır. Uçucu yağların yapısında yer alan monoterpenlerin hücre içine hızlı bir şekilde nüfuz ederek hücre içi yapılarına zarar vermesi (Abrahim et al., 2000), bitkilerin krolofil oranını düşürmesi (Kong et al., 1999), oksijen tüketimini azaltması (Penuelans et al., 1996) gibi etkileri nedeniyle tohum çimlenmesi ve bitki gelişimini engellendiği bildirilmiştir. Ayrıca hücre zarının yapısını oluşturan yağ asitleri ve lipitleri uçucu yağların yapısında bulunan oksijen türevli maddelerin lipid peroksidasyona uğratması ile hücresel yapılarını bozduğu bildirilmiştir (Scrivanti et al., 2003).

Uçucu yağların yabancı otlar üzerine çimlenmeyi, büyümeyi ve gelişmeyi engelleyici allelopatik etki göstermesi ve biyolojik olarak doğada sentetik herbisitlere göre daha kolay parçalanabilme özelliklerinin olmasından dolayı bitkisel kökenli uçucu yağlar yabancı ot kontrolünde herbisitlere alternatif olarak gösterilmektedir. Ayrıca her geçen gün önemi giderek artan organik tarımda yabancı ot mücadelesinde kimyasal yabancı ot ilaçlarının kullanımına izin verilmemesi, yabancı otların mücadelesinde uçucu yağlar gibi doğal allelokimyasalların kullanılabilirliklerinin araştırıması üzerine çalışmalar yoğunlaşmıştır. Çalışmalar ile belirlenen biyoherbisit özelliği gösteren uçucu yağların elde edildiği bitkiler ve bu uçucu yağlardan etkilenen bitki türleri Çizelge 1 'de verilmiştir.

Çizelge 1. Uçucu yağ bitkilerinin allelopatik etkileri.

Table 1. The allelopathic effects of essential oil plants.

\begin{tabular}{|c|c|c|}
\hline Uçucu yağların elde edildiği bitki türleri & Uçucu yağlardan etkilenen bitki türleri & Kaynaklar \\
\hline $\begin{array}{l}\text { Salvia officinalis L. (Adaçayı), Origanum } \\
\text { onites L. (İzmir kekiği), Mentha spicata L. } \\
\text { (Kıvırcık nane), Coriandrum sativum L. } \\
\text { (Kişniş), Thybmra spicata L. (Karabaş kekik), } \\
\text { Rosmarinus officinalis L. (Biberiye), } \\
\text { Pimpinella anisum L. (Anason), Lavandula } \\
\text { stoechas L. (Karabaş otu), Carum carvi L. } \\
\text { (Frenk kimyonu), Foeniculum vulgare Mill. } \\
\text { (Rezene). }\end{array}$ & $\begin{array}{l}\text { Sinapis arvensis L. (Yabani hardal), } \\
\text { Rumex nepalensis Spreng. (Irmak } \\
\text { labadası), Raphanus raphanistrum L. } \\
\text { (Yabani turp), Alcea pallida Waldst. and } \\
\text { Kit. (Hatmi), Amaranthus retroflexus L. } \\
\text { (Horoz ibiği), Sonchus oleraceus L. } \\
\text { (Eşek marulu), Centaurea solstitialis L. }\end{array}$ & (Azırak 2002) \\
\hline Artemisia vulgaris L. (Misk otu) & $\begin{array}{l}\text { Xanthium strumarium L. (Büyük pıtrak), } \\
\text { Medicago sativa L. (Yonca), Lolium } \\
\text { perenne L. (İngiliz çimi), Agrostemma } \\
\text { githago L., Amaranthus retroflexus L. } \\
\text { (Horoz ibiği), Cardaria draba (L.) Desv., } \\
\text { Chenopodium album L. (Sirken), } \\
\text { Echinochloa crus-galli (L.) P. Beauv., } \\
\text { Reseda lutea L., Rumex crispus L. } \\
\text { (Labada), Trifolium pratense L. (Çayır } \\
\text { üçgülü), Trifolium spp. (Üçgüller), } \\
\text { Triticum spp. (Buğday), Lycospersicon } \\
\text { esculantum L., Brassica oleracea L., } \\
\text { Daucus carota L., Cucumis sativus L. } \\
\text { (Hıyar), Lepidium sativum L., Medicago } \\
\text { sativa L. (Yonca) }\end{array}$ & $\begin{array}{l}\text { (Önen et al., 2002; Önen and } \\
\text { zer 2002) }\end{array}$ \\
\hline
\end{tabular}


Çizelge 1. Devamı.

Table 1. Continue.

\begin{tabular}{|c|c|c|}
\hline Uçucu yağların elde edildiği bitki türleri & Uçucu yağlardan etkilenen bitki türleri & Kaynaklar \\
\hline Eucalyptus citriodora (Ökaliptüs) & $\begin{array}{l}\text { Cassia odientalis L., Bidens pilosa L., } \\
\text { Avena fatua L. (Yabani yulaf) ve } \\
\text { Ageratum conyzoides L. }\end{array}$ & (Singh et al., 2002) \\
\hline $\begin{array}{l}\text { Artemisia vulgaris L. (Adi pelin), Mentha } \\
\text { spicata L. subps. spicata (Nane), Ocimum } \\
\text { basilicum L. (Fesleğen), Salvia officinalis L. } \\
\text { (Adaçayı), Thymbra spicata L. subsp. } \\
\text { Spicata (Zahter) }\end{array}$ & $\begin{array}{l}\text { Artemisia vulgaris L. (Pelin), Xanthium } \\
\text { strumarium L. (Koca pitrak), Medicago } \\
\text { sativa L. (Yonca), Lolium perenne } \\
\text { L.(İngiliz çimi) }\end{array}$ & (Önen 2003) \\
\hline Eucalptus citriodora Hook. & $\begin{array}{l}\text { Triticum aestivum L. (Ekmeklik } \\
\text { buğday), Zea mays L. (Mısır), ve } \\
\text { Raphanus sativus L. (Turp), Echinochloa } \\
\text { crus-galli L. Beauv., Cassia occidentalis } \\
\text { L., Amaranthus viridis L. Parthenium } \\
\text { hysterophorus L. }\end{array}$ & $\begin{array}{l}\text { (Batish et al., 2004; Singh et al., } \\
\text { 2005) }\end{array}$ \\
\hline Syzygium aromaticum L. (Karanfil) & $\begin{array}{l}\text { Amaranthus retroflexus (Horoz ibiği), } \\
\text { Chenopodium album (Sirken), Brassica } \\
\text { oleraceae var. italica (Brokoli) }\end{array}$ & (Bainard et al., 2006) \\
\hline Laurus nobilis L. (Akdeniz defnesi) & $\begin{array}{l}\text { Triticum aestivum (Ekmeklik buğday), } \\
\text { Zea mays L. (Mısır), Gossypium } \\
\text { hirsutum L. (Pamuk), Amaranthus } \\
\text { retroflexus (Horoz ibiği), Glycyrrhiza } \\
\text { glabra L. (Meyan), Rumex crispus L. } \\
\text { (Labada), Physalis angulata L. } \\
\text { (Güveyfeneri) }\end{array}$ & (Çetintaş et al., 2006) \\
\hline $\begin{array}{l}\text { Tanacetum aucheranum, Tanacetum } \\
\text { chiliophyllum var. chiliophyllum }\end{array}$ & $\begin{array}{l}\text { Amaranthus retroflexus (Horoz ibiği), } \\
\text { Rumex crispus (Labada), Chenopodium } \\
\text { album (Sirken) }\end{array}$ & (Salamcı et al., 2007) \\
\hline Origanum acutidens (Zemul) & $\begin{array}{l}\text { Amaranthus retroflexus (Horoz ibiği), } \\
\text { Chenopodium album (Sirken), Rumex } \\
\text { crispus (Labada) }\end{array}$ & (Kordali et al., 2008) \\
\hline Lavandula spp. (Lavanta) & Lolium rigidum & (Haig et al., 2009) \\
\hline $\begin{array}{l}\text { Ocimum basilicum (Fesleğen), Lavandula } \\
\text { angustifolia (Lavanta), Thymus vulgaris } \\
\text { (Kekik), Salvia officinalis (Adaçayı), Melissa } \\
\text { officinalis (Oğulotu) }\end{array}$ & $\begin{array}{l}\text { Xanthium strumarium (Pıtrak), Phalaris } \\
\text { brachystachys (Kuş Yemi), Avena sterilis } \\
\text { (Yabani Yulaf) }\end{array}$ & (Üremiş et al., 2009) \\
\hline $\begin{array}{l}\text { Origanum dubium L. (Kekik), Allium cepa L. } \\
\text { (Soğan), Allium sativum L. (Sarımsak) }\end{array}$ & $\begin{array}{l}\text { Rumex crispus L. (Labada), Amaranthus } \\
\text { retroflexus L. (Horoz İbiği), Sinapsis } \\
\text { arvensis L. (Horoz ibiği), Physalis } \\
\text { angulata L. (Güveyfeneri) }\end{array}$ & (Aydın ve Tursun 2010) \\
\hline $\begin{array}{l}\text { Cinnamomum zeylanicum L., Lavandula } \\
\text { spp.(Lavanta), Mentha x piperita L. (Nane) }\end{array}$ & $\begin{array}{l}\text { Amaranthus retroflexus L. (Horoz İbiği). } \\
\text { Solanum nigrum L., Portulaca oleracea } \\
\text { L., Chenopodium album L. (Sirken), } \\
\text { Sinapis arvensis L. (Yabani Hardal), } \\
\text { Lolium spp. (Çim), Vicia sativa L. }\end{array}$ & (Cavalieri and Caporali 2010) \\
\hline
\end{tabular}


Çizelge 1. Devamı.

Table 1. Continue.

\begin{tabular}{|c|c|c|}
\hline Uçucu yağların elde edildiği bitki türleri & Uçucu yağlardan etkilenen bitki türleri & Kaynaklar \\
\hline $\begin{array}{l}\text { Thymus fallax Fisch. \& Mey. (Kekik), } \\
\text { Origanum vulgare L. (Güveotu), Mentha } \\
\text { dumetorum Schult. }\end{array}$ & $\begin{array}{l}\text { Avena sterilis L., Datura stramonium L. } \\
\text { (Boru çiçeği), Cucumis sativus L. (Hıyar), } \\
\text { Lactuca sativa L. (Marul) }\end{array}$ & (Yılar et al., 2011) \\
\hline Artemisia scoparia Waldst. Et Kit & $\begin{array}{l}\text { Abutilon theoprastii Medik (Hint Keneviri), } \\
\text { Agrostemma githago L., Rumex crispus L. } \\
\text { (Labada), Sinapis arvensis L. (Yabani } \\
\text { hardal), Amaranthus retroflexus L. (Horoz } \\
\text { ibiği), Chenopdium album L. (Ak kaz } \\
\text { ayağı), Lactuca sativa L. (Marul), Lepidium } \\
\text { sativum L. (Tere) }\end{array}$ & (Yılar et al., 2012) \\
\hline $\begin{array}{l}\text { Rosmarinus officinalis (Biberiye), Salvia } \\
\text { officinalis (Adaçayı), ve Origanum onites } \\
\text { (Güveyotu) }\end{array}$ & $\begin{array}{l}\text { Amaranthus hybridus (Melez mancar), } \\
\text { Physalis angulata (Çukurova fener otu) ve } \\
\text { Portulaca oleracea (Semizotu) }\end{array}$ & (Şahin et al., 2013) \\
\hline Linum persicum (Acem keteni) & $\begin{array}{l}\text { Lactuca sativa (Marul), Raphanus sativus } \\
\text { (Turp) }\end{array}$ & (Azizi and Fuji 2006) \\
\hline Eucalyptus globulus (Ökaliptüs) & $\begin{array}{l}\text { Amaranthus retroflexus (Horoz ibiği), } \\
\text { Portulacea oleracea }\end{array}$ & (Azizi and Fuji 2006) \\
\hline Salvia officinalis L. (Adaçayı) & $\begin{array}{l}\text { Amaranthus retroflexus L. (Horoz ibiği), } \\
\text { Rumeex crispus L., Sinapis arvensis L. } \\
\text { (Yabani hardal), Triticum aestivum var. } \\
\text { Gün91. (Buğday), Helianthus annuus var. } \\
\text { Sirena. (Ayçiçeği), Cicer arietinum (Nohut) }\end{array}$ & (Erbaş ve ark., 2011a) \\
\hline
\end{tabular}

Lavandula $x$ intermedia Emeric ex Loisel. Sinapis arvensis L. (Yabani hardal) $\quad$ (Erbaş et al., 2011b) (Lavanta)

Thymus vulgaris (Kekik) Amarathus retroflexus L. (Horoz ibiği),

(Üremiş ve ark., 2014) Portulaca oleracea L., Physalis angulata L., Solanum nigrum L. (İt üzümü)

Coriandrum sativum L. (Kişniş), Foeniculum Lathyrus annuus (Mürdümük), Vicia vulgare (Rezene), Carum carvi (Kimyon), villosa (Yalancı tüylü fiğ)

Cuminum cyminum L. (Yeşil kimyon)

\begin{tabular}{|c|c|c|}
\hline $\begin{array}{l}\text { Parthenium hysterophorus, Ambrosia } \\
\text { polystachya (Kanarya otu) }\end{array}$ & Lactuca sativa L. (Marul) & (Miranda et al., 2014) \\
\hline Artemisia scoparia Waldst et Kit. & $\begin{array}{l}\text { Achyranthes aspera, Cassia occidentalis } \\
\text { (Sinameki), Parthenium hysterophorus, } \\
\text { Echinochloa crus-galli, Ageratum } \\
\text { conyzoides. }\end{array}$ & (Kaur et al., 2010) \\
\hline $\begin{array}{l}\text { Carum carvi L. (Kimyon), Coriandrum } \\
\text { sativum L. (Kişniş), Foeniculum vulgare Mill. } \\
\text { (Rezene), Lavandula stoechas L. (Karabaş } \\
\text { otu), Mentha spicata L. (Nane), Origanum } \\
\text { onites L. (Güveyotu), Pimpinella anisum L. } \\
\text { (Anason), Rosmarinus officinalis L. } \\
\text { (Biberiye), Salvia officinalis L. (Adaçayı), } \\
\text { Thymbra spicata L. (Zahter) }\end{array}$ & $\begin{array}{l}\text { Alcea pallida Waldst. \& Kit., Amaranthus } \\
\text { retroflexus L. (Horoz ibiği), Centaurea } \\
\text { salsotitialis L., Raphanus raphanistrum L., } \\
\text { Rumex nepalensis Spreng., Sinapis } \\
\text { arvensis L. (Yabani hardal), Sonchus } \\
\text { oleraceus L. }\end{array}$ & (Azirak and Kahraman 2007) \\
\hline
\end{tabular}


Çizelge 1. Devamı.

Table 1. Continue.

\begin{tabular}{lll}
\hline Uçucu yağların elde edildiği bitki türleri & Uçucu yağlardan etkilenen bitki türleri & Kaynaklar \\
\hline Eucalyptus globulus (Ökaliptus) & $\begin{array}{l}\text { Amaranthus blitoides (Mor darımancarı), } \\
\text { Cynodon dactylon (Köpek dişi) }\end{array}$ & (Rassaeifar et al., 2013) \\
\hline Mentha spicata L. subsp. Spicata (Nane), & $\begin{array}{l}\text { Rumex crispus L. (Labada), Setaria glauca } \\
\text { Laurus nobilis L. (Akdeniz defnesi), }\end{array}$ & (Y.) P. Beauv (Yabani darı), Abutilon \\
Foeniculum vulgare Mill.(Rezene), Satureja & theoprasti (L.) Medik. (Hatmi), Taraxacum & \\
montana L.(Geyikotu), Origanum onites L. & officinale L. (Karahindiba), Amaranthus & \\
(Güveyotu), Coriandrum sativum L. (Kişniş) & $\begin{array}{l}\text { retroflexus L. (Horoz ibiği), Daucus carota } \\
\text { L. (Havuç), Thlaspi arvense L. (Tarla }\end{array}$ & \\
& $\begin{array}{l}\text { akçeçiçeği), Poa annua L. (Salkım otu), } \\
\text { Chenopodium album L. (Sirken), Avena } \\
\text { sterilis L. (Kısır yulaf) }\end{array}$ \\
\hline
\end{tabular}

\section{SONUÇ}

Son yıllarda kimyasal herbisitlerin insan sağlığına ve çevreye olan zararlarından dolayı yabancı ot mücadelesinde uçucu yağlar gibi doğal allelokimyasalların kullanılabilirliklerinin araştırılması üzerine çalışmalar yoğunlaşmıştır. Fakat uçucu yağların herbisidal etkileri üzerine çok sayıda çalışma yapılmasına rağmen bu çalışmaların çoğu laboratuvar koşullarında sınırlı kalmış ve çok azında kültür bitkilerine yer verilmiştir. Uçucu yağlardan istenen faydanın sağlanabilmesi için yabancı otlara etki gösterirken kültür bitkilerine etki göstermemesi gerekir. Dolayısıyla uçucu yağların direk kullanımlarından ziyade uçucu yağların bileşenlerinin belirlenmesi, bunların tek başlarına ve sinerjik etkilerinin araştırılarak çeşitli formülasyonların geliştirilmesi ve bu formülasyonların yabancı otlar ile birlikte kültür bitkileri üzerinde de denenmesinde fayda vardır. Bunlara ek olarak etkili bulunan formülasyonlara kontrollü salınım sistemleri uygulanarak etki sürelerinin artırılmasında önemlidir. Bu bağlamda, daha çok araştırmanın yapılması ve pratikte sonuç veren arazi çalışmalarının artması gerekmektedir.

\section{KAYNAKLAR}

Abrahim D., Braguini WL., Kelmer-Brach AM and IshiiIwamoto EL., 2000. Effect of four monoterpenes on germination, primary root growth, an mitochondrial respiration of maize. Journal of Chemical Ecology, 26: 611-624.

Amini RA, Movahedpour F., Ghassemi-Golezani K., Dabbagh Mohammadi-Nasab A and Zafarani-Moattar P., 2012. Allelopathic assessment of common amaranth by ECAM. International Research Journal of Applied and Basic Sciences, 3: 2268-2272.
Amini RA., 2013. Allelopathic potential of little seed canary grass (Phalaris minor Retz.) on seedling growth of barley (Hordeum vulgare L.). Journal of Biodiversity and Environmental Sciences, 3: 85-91.

Aydın O ve Tursun N., 2010. Bitkisel kökenli bazı uçucu yağların bazı yabancı ot tohumlarının çimlenme ve çıkışına olan etkilerinin araştırılması. Kahramanmaraş sütçü İmam Üniversitesi Doğa Bilimler Dergisi, 1(1): 1117.

Azırak S., 2002. Bazı uçucu yağ bitkilerinin ve aromakimyasalların yabancı ot türlerinin çimlenmesi üzerine allelopatik etkisi. Yüksek Lisans Tezi (Basılmamış), Sütçü İmam Üniversitesi Fen Bilimleri Enstitüsü, Kahramanmaraş.

Azirak S and Kahraman S., 2007. Allelopathic effect of some essential oils and components on germination of weed species. Acta Agriculturae Scandinavica, Section B-Soil and Plant Science, 58: 88-92.

Azizi M and Fuji Y., 2006. Allelopathic effect of some medicinal plant substances on seed germination of Amaranthus retroflexus and Portulaca oleraceae. Acta horticulturae, 699: 61-67.

Bainard LD., Isman MB and Upadhyaya MK., 2006. Phytotoxicity of clove oil and its primary constituent eugenol and the role of leaf epicuticular wax in the susceptibility to these essential oils. Weed Science, 54(5): 833-837.

Barney JN., Hay AG and Weston LA., 2005. Isolation and characterization of allelopathic volatiles from mugwort (Artemisia vulgaris). Journal of Chemical Ecology, 31: 247-265.

Batish DR., Kaur S., Singh HP and Kohli RK., 2004. Herbicidal Activitiy of Volatile Oils from Eucalyptus citriodora. II. European Allelopathy Symposium, 3-5 June, Poland.

Baydar H., 2005. Yayla kekiği (Origanum minutiflorum O. Schwarz et. P.H. Davis)'nde farklı toplama zamanlarının 
uçucu yağ içeriği ve uçucu yağ bileşenleri üzerine etkisi. Akdeniz Üniversitesi Ziraat Fakültesi Dergisi, 18: 175-178.

Baydar H., 2009. Tıbbi ve Aromatik Bitkiler Bilimi ve Teknolojisi. Süleyman Demirel Üniversitesi Yayınları, Yayın No: 51, Isparta.

Baydar H., 2013. Tıbbi Aromatik ve Keyf Bitkileri Bilimi ve Teknolojisi. Süleyman Demirel Üniversitesi Yayınları, Yayın No: 51, Isparta.

Cavalieri A and Caporali F., 2010. Effects of essential oils of cinnamon, lavender and peppermint on germination of Mediterranean weeds. Allelopathy Journal, 25(2): 441451.

Ceylan A., 1987. Tıbbi bitkiler II (Uçucu Yağ İçerenler). Ege Üniversitesi Ziraat Fakültesi Yayınları, Yayın No: 481, İzmir.

Çetintaş R., Tursun N., Karcı A., Almira MH and Seyithanoğlu M., 2006. The Bioherbicidal effects of daphne (Laurus nobilis L.) and some of its important components on the germination of some weeds and agronomic crops. Annual International Research Conference on Methyl Bromide Alternatives and Emissions Reductions, 6-9 November, USA.

Dağ SS., Aykaç VT., Gündüz A., Kantarcı M ve Şişman N., 2000. Türkiye'de Tarım İlaçları Endüstrisi ve Geleceği. Türkiye Ziraat Mühendisliği V. Teknik Kongresi, 17-21 Ocak, Ankara.

Delen N., Durmuşoğlu E., Güncan A., Güngör N., Turgut $C$ ve Burçak A., 2005. Türkiye'de Pestisit Kullanımı, Kalıntı ve Organizmalarda Duyarlıık Azalışı Sorunları. Ziraat Mühendisliği VI. Teknik Kongresi, 3-7 Ocak, Ankara.

Duke SO., 1991. Plant terpenoids as pesticides. Toxicology of Plant and Fungal Compounds (eds, RF. Keeler and AT Tu), Marcel Dekker, pp. 269-296.

Erbaş S., Elkoyunu R ve Baydar H., 2011a. Bazı Yabancı Ot ve Kültür Bitkisi Tohumlarının Çimlenmesi ve Fide Gelişimi Üzerine Salvia officinalis L. Uçucu Yağının Allelopatik Etkisi. IX. Tarla Bitkileri Kongresi, 12-15 Eylül, Bursa.

Erbaş S., Özen F and Baydar H., 2011b. Allelopathic Effect of Lavandin Oil and Major Component on Germination and Seedling Development of Wild Mustard (Sinapis arvensis L.). II. International Non-Wood Forest Products Symposium, 8-10 September, Isparta.

Feo V., Simone F and Senatore F., 2002. Potential allelochemicals from the essential oil of Ruta graveolens. Phyochemistry, 61: 573-578.

Gholami BA., Faravani M and Kashki MT., 2011. Allelopathic effects of aqueous extract from Artemisia kopetdaghensis and Satureja hortensis on growth and seed germination of weeds. Journal of Applied Environmental and Biological Sciences, 1: 283-290.

Haig TJ., Haig TJ., Seal AN., Pratley JE., An M and Wu H., 2009. Lavender as a source of novel plant compounds for the development of a natural herbicide. Journal of Chemical
Ecology, 35: 1129-1136.

Handa SS., Khanuja SPS., Longo G and Rakesh DD., 2008. Extraction Technologies for Medicinal and Aromatic Plants. International Centre for Science and High Technology, Italy.

Kaur S., Singh HP., Mittal S., Batish DR and Kohli RK., 2010. Phytotoxic effects of volatile oil from Artemisia scoparia against weeds and its possible use as a bioherbicide. Industrial Crops and Products, 32: 54-61.

Khanh TD., Chung MI., Xuan TD and Tawata S., 2005. The exploitation of crop allelopathy in sustainable Agricultural production. Jornal of Agronomy and Crop Science, 191: 172-184.

Khan AL., Hussain J., Hamayun M., Kang SM., Kim HY., Watanabe KN and Lee IN., 2010. Allelochemical, eudesmane-type sesquiterpenoids from Inula falconeri. Molecules Journal, 15: 1554-1561.

Kong C., Hu F., Xu T and Lu Y., 1999. Allelopathic potential and chemical constituents of volatile oil from Ageratum conyzoides. Journal of Chemical Ecology, 25: 2347-2356.

Konstantinović B., Blagojević M., Konstantinović B and Samardžić N., 2104. Allelopathic effect of weed species Amaranthus retroflexus L. on maize seed germination. Romanian Agricultural Research, 31: 315-321.

Kordali S., Cakir A., Ozer H., Cakmakcı R., Kesdek M and Mete E., 2008. Antifungal, phytotoxic and insecticidal properties of essential oil isolated from Turkish Origanum acutidens and three components, carvacrol, thymol and p-cymene. Bioresouarce Technology, 99: 8788-8795.

Kordali S., Cakir A., Akcin TA, Mete E., Akcin A., Aydin T and Kilic H., 2009. Antifungal and herbicidal properties of essential oils and $n$-hexane extracts of Achillea gypsicola Hub-Mor. and Achillea biebersteinii Afan. (Asteraceae). Industrial Crops and Products, 29(2-3): 562-570.

Kwiecińska-Poppe E., Kraska P and Pałys E., 2011. The influence of water extracts from Galium aparine L. and Matricaria maritime subsp. inodora (L.) Dostál on germination of winter rye and triticale. Acta Scientarum Polonurum Agricultura, 10: 75-85.

Luciana AG., Carpenese G., Ciani P.L., Morelli I., Macchia M and Flamini G., 2003. Essential oil from Mediterranean Lamiaceae as germination inhibitors. Journal of Agricultural and Food Chemistry, 51: 6158-6164.

Mengüllüoğlu M and Soylu S., 2012. Antibacterial activities of essential oils from several medicinal plants against the seed-borne bacterial disease agent Acidovorax avenae subsp. citrulli. Research on Crops, 13: 641-646.

Miranda CASF., Maria das G. Cardoso MG., Carvalho MLM., Figueiredo ACS., Nelson DL., Oliveira CM., Gomes MS., Andrade J., Souza JA and Albuquergue LRM., 2014. Chemical composition and allelopathic activity of Parthenium hysterophorus and Ambrosia polystachya 
weeds essential oils. American Journal of Plant Sciences, 5: $1248-1257$.

Oerke EC., Dehwe HW., Schonbeck F and Weber A., 1994. Crop Production and Crop Protection. Estimated Losses in Major Food and Cash Crops, Elsevier Science.

Önen H., 2003. Bazı bitkisel uçucu yağların biyoherbisidal etkileri. Türkiye Herboloji Dergisi, 6: 39-47.

Önen $\mathrm{H}$ and Özer Z., 2002. Study of allelopatic on several crups. influence of mugwort (Artemisia vulgaris L.). Journal Plant Disease and Protection Sonderheft, 18: 339-347.

Önen H., Özer Z and Telci İ., 2002. Bioherbicidal effects of some plant essential oils on different weed species. Journal of Plant Diseases and Protection Sonderheft, 18: 597-605.

Penuelans J., Ribas-Carbo M and Giles L., 1996. Effects of allelochemicals on plant respiration and oxygen isotope fractionation by the alternative oxidase. Journal of Chemical Ecology, 22: 801-805.

Radosevich S., Holt J and Ghersa G., 1997. Weed Ecology: Implictions for Management. $2^{\text {nd }}$. John Wily \& Sons.

Rahimi AR., Mousavizadeh SJ., Mohammadi H., Rokhzadi A., Majidi M and Amini S., 2013. Allelopathic effect of some essential oils on seed germination of Lathyrus annuus and Vicia villosa. Journal of Biodiversity Environmental Sciences, 3: 67-73.

Rassaeifar M., Hosseini N., Asl NHH., P. Zandi P and Moradi Aghdam AM., 2013. Allepathic effect of Eucalyptus globulus' essential oil on seed germination and seedling establishment of Amaranthus blitoides and Cynodon Dactylon. Trakia Journal of Sciences, 1: 73-81.

Reynolds T., 1987. Comparative effect of alicyclic compunds and quinones on inhibition of lettuce fruit germination. Annals of Botany, 60: 215-223.

Rice EL., 1984. Allelopathy. Academic Press, pp. 130-188.

Robinson JB., 1983. The Organic Constituents of Higher Plants. Cordus Press.

Robles C., Bonın G and Garzino S., 1996. Auotoxic and allelopathic potentials of Citrus albidus L. Plant Biology and Pathology, 322: 677-685.

Salamci E., Kordali S., Kotan R., Cakir A and Kaya Y., 2007. Chemical composition, antimicrobial and herbicidal effects of essential oils isolated from Turkish Tanacetum aucheranum and Tanacetum chiliophyllum var. chiliophyllum. Biochemical Systematics and Ecology, 35: 569-581.

Scrivanti LR., Zunino MP and Zygadlo JA., 2003. Tagetes minuta and Schinus areira essential oils as allelopathic agents. Biochemical Systematics and Ecology, 31(6): 563572.

Sertkaya E., 2013. Fumigant toxicity of the essential oils from medicinal plant against bean weevil, Acanthoscelides obtectus (Say) (Coleoptera: Bruchidae). Asian Journal of Chemistry, 25(1): 553-555.

Singh HP., Batish DR., Kaur S., Ramezani H and Kohli RK., 2002. Comparative phytotoxicity of four monoterpenes against Cassia occidentalis. Annals of Applied Biology, 141: 11-116.

Singh HP., Batish DR., Setia N and Kohli R.K., 2005. Herbicidal activity of volatile oils from Eucalyptus citriodora against Parthenium hysterophorus. Annals of Applied Biology, 146: 89-94.

Soltys D., Krasuska U., Bogatek R and Gniazdowska A., 2013. Allelochemicals as bioherbicides-present and perspectives. V: Herbicides-Curent Research and Case Studies in Use (Eds. AJ. Price and Kelton JA), InTech Publisher, Rijeka, Croatica, pp. 517-542.

Soylu EM., Soylu S and Kurt S., 2006. Antimicrobial activities of the essential oils of various plants against tomato late blight disease agent Phytophthora infestans. Mycopathologia, 161: 119-128.

Soylu S., Evrendilek GA and Soylu EM., 2009. Chemical compositions and antibacterial activities of bitter fennel (Foeniculum vulgare Mill. var. vulgare) and dill (Anethum graveolens L.) essential oils against the growth of foodborne and seed-borne plant pathogenic bacteria. Italian Journal of Food Science, 21: 347-355.

Şahin CB., Arslan M ve Kırmaz S., 2013. Bazı Yabancı Ot Tohumlarının Çimlenmesi Üzerine Uçucu Yağların Herbisidal Etkisi. 10. Tarla Bitkileri Kongresi, 10-13 Eylül, Konya.

Telci ì., 2006. Uçucu Yağlar ve Allelopati. Allelopati Çalıştayı, 13-15 Haziran, Yalova.

Thobatsi T., 2009. Growth and yield responses of maize (Zea mays L.) and cowpea (Vigna unguiculatea) in a intercropping system. MSc Thesis, University of Pretoria, Pretoria.

Uludağ A., 2006. Türkiye'de Allelopati Araştırmaları ve Uygulamaları Üzerine Genel Bir Bakış. Allelopati Çalıştayı, 13-15 Haziran, Yalova.

Uygur FN., 2002. Yabancı Otlar ve Biyolojik Mücadele. Türkiye 5. Biyolojik Mücadele Kongresi, Atatürk Üniversitesi Ziraat Fakültesi, 4-7 Eylül, Erzurum.

Üremiş İ., Arslan M., Yıldırım AE ve Soylu S., 2014. Bazı Kekik Uçucu Yağlarının Yabancı Ot Mücadelesinde Toprak Fumigantı Olarak Kullanılabilme Olanaklarının Belirlenmesi. V. Bitki Koruma Kongresi, 3-5 Şubat, Antalya.

Üremis I., Arslan M and Sangun MK., 2009. Herbicidal potential of essential oils on the germination of some problem weeds. Asian Journal of Chemistry, 21(4): 31993210.

Yılar M., Bayan Y., Töre Ö., Akşit H ve Kadıoğlu İ., 2011. Thymus Fallax Fisch.\&Mey., Mentha Dumetorum Schult. ve Origanum vulgare LI. Bitkilerinden İzole Edilen Uçucu 
Özen ve ark., Yabancı Ot Mücadelesinde Bazı Aromatik Bitkilerinin Uçucu Yağlarının Allelopatik Etkisi

Yağların Biyoherbisidal Etkileri. IV. Bitki Koruma Kongresi, Kahramanmaraş Sütçü İmam Üniversitesi, 28-30 Haziran, Kahramanmaraş.

Yılar M., Bayan Y., Özcan S., Akşit H ve Kadıoğlu İ., 2012. Artemisia scoparia Waldst. et Kit. uçucu yağının biyoherbisidal etkisi. Gümüşhane Üniversitesi Fen Bilimleri Enstitüsü Dergisi, 2(1): 11-20.

Yıldırım BK., 2007. Bazı bitkisel kökenli uçucu yağların bioherbisidal etkilerinin araştırılması. Yüksek Lisans Tezi (Basılmamış), Ondokuz Mayıs Üniversitesi Fen Bilimleri Enstitüsü, Samsun. 